\title{
PENGARUH SENAM HIPERTENSI LANSIA TERHADAP TEKANAN DARAH LANSIA DENGAN HIPERTENSI DI WILAYAH KERJA PUSKESMAS CAKRANEGARA KELURAHAN TURIDA TAHUN 2019
}

\author{
Ni Putu Sumartini ${ }^{1}$, Zulkifli ${ }^{2}$, Made Anandam Prasetya Adhitya ${ }^{3}$ \\ 1, 2, 3 Jurusan Keperawatan, Poltekkes Kemenkes Mataram, Indonesia
}

\begin{abstract}
Abstrak
Hipertensi adalah suatu keadaan dimana seseorang mengalami peningkatan tekanan darah di atas normal yang mengakibatkan peningkatan angka kesakitan (morbiditas) dan angka kematian (mortalitas). Hipertensi pada lansia didefinisikan dengan tekanan sistolik di atas $160 \mathrm{mmHg}$ dan tekanan diastolik diatas $90 \mathrm{mmHg}$. Senam hipertensi merupakan olah raga yang salah satunya bertujuan untuk meningkatkan aliran darah dan pasokan oksigen ke dalam otot-otot dan rangka yang aktif khususnya otot jantung sehingga dapat menurunkan tekanan darah. Tujuan penelitian ini adalah untuk mengetahui pengaruh senam hipertensi lansia terhadap tekanan darah lansia dengan hipertensi di wilayah kerja Puskesmas Cakranegara Kelurahan Turida Tahun 2019. Metode penelitian ini menggunakan metode rancangan pra-eksperimen, one group pretest-posttest. Jumlah sampel 30 orang yang diambil dengan teknik Purposive Sampling. Pengumpulan data dengan observasi tekanan darah sebelum dan sesudah intervensi, yang dilakukan dua kali seminggu selama empat minggu. Data tekanan darah dianalisa menggunakan paired sampel t-test dengan $\alpha<0,05$. Hasil penelitian menunjukkan rata-rata tekanan darah sistolik sebelum senam hipertensi lansia $151,80 \mathrm{mmHg}$, diastolik $94,73 \mathrm{mmHg}$ dan rata-rata tekanan darah sistolik sesudah senam hipertensi lansia $137,13 \mathrm{mmHg}$, diastolik 90,27 mmHg. Hasil uji paired sampel t-test didapatkan $\mathrm{p}=0,000<\alpha=0,05$ sehingga $\mathrm{H} 0$ ditolak H1 diterima. Kesimpulan pada penelitian ini adalah ada pengaruh yang signifikan senam hipertensi lansia terhadap tekanan darah lansia dengan hipertensi di wilayah kerja Puskesmas Cakranegara Kelurahan Turida Tahun 2019. Saran bahwa senam hipertensi lansia dapat menjadi alternatif senam yang dapat diberikan pada lansia yang mengikuti program Prolanis maupun kegiatan olahraga lain.
\end{abstract}

Kata Kunci : Tekanan darah, Senam Hipertensi, Lansia

\section{EFFECT OF ELDERLY HYPERTENSION GYMNASTICS ON ELDERLY BLOOD PRESSURE WITH HYPERTENSION IN THE WORK AREA OF CAKRANEGARA HEALTH CENTER IN TURIDA VILLAGE IN 2019}

\begin{abstract}
Hypertension is a condition when a person experienced an increase in blood pressure above normal which results in increasing morbidity and mortality. Hypertension in the elderly is defined as systolic pressure above $160 \mathrm{mmHg}$ and diastolic pressure above $90 \mathrm{mmHg}$. Elderly hypertension gymnastics is a sport aims to increase blood flow and oxygen supply to the muscles and skeletons that are active, especially the heart muscle so that it can reduce blood pressure. The purpose of this study was to determine the effect of elderly hypertension gymnastics on the blood pressure of the elderly with hypertension in the working area of Cakranegara Public Health Center in Turida on 2019. The research method used was a pre-experimental design method, one group pretest-posttest. The number of samples were 30 people taken by purposive sampling technique. Data collected by observing blood
\end{abstract}


pressure before and after the intervention was carried out, twice a week for four weeks, then analyzed using paired sample t-test with $\alpha=0.05$. The results showed the average systolic blood pressure before gymnastics elderly hypertension was $151.80 \mathrm{mmHg}$, diastolic $94.73 \mathrm{mmHg}$. Average systolic blood pressure after hypertension gymnastics elderly was $137.13 \mathrm{mmHg}$, diastolic $90.27 \mathrm{mmHg}$. Paired sample t-test results $\mathrm{b}=0,000<\alpha=0.05$ so that $\mathrm{H} 0$ is rejected $\mathrm{H} 1$ is accepted. The conclusion of this study is that there is a significant influence of elderly hypertension gymnastics on the blood pressure of elderly with hypertension in the working area of Cakranegara Public Health Center, Turida Village on 2019.

\section{Keywords: blood pressure, hypertension gymnastics, elderly}

\section{PENDAHULUAN}

Hipertensi adalah suatu keadaan dimana seseorang mengalami peningkatan tekanan darah di atas normal yang mengakibatkan peningkatan angka kesakitan (morbiditas) dan angka kematian (mortalitas) (Kushariyadi, 2011). Hipertensi pada lansia didefinisikan dengan tekanan sistolik di atas $160 \mathrm{mmHg}$ dan tekanan diastolic diatas $90 \mathrm{mmHg}$ (Fatimah, 2010). Menurut Joint National Committee on Prevention, Detection, Evaluation, and Treatment on High Blood Pressure VII (JNCVII), hampir 1 milyar orang menderita hipertensi di dunia. Menurut laporan Badan Kesehatan Dunia atau WHO, hipertensi merupakan penyebab nomor 1 kematian di dunia dan dan diperkirakan, jumlah penderita hipertensi akan terus meningkat seiring dengan jumlah penduduk yang membesar. Hipertensi di Indonesia pada usia lebih dari 18 tahun sebesar 34,1\% dan tertinggi di Kalimantan Selatan sebesar 44,1\%. Prevalensi hipertensi pada umur 18 tahun ke atas di Provinsi NTB yakni mencapai 24,3\% (Riset Kesehatan Dasar, 2018). Berdasarkan Profil Dinas Kesehatan Provinsi Nusa Tenggara Barat dari 10 Penyakit Terbanyak yang ada di Nusa Tenggara Barat Tahun 2016 Hipertensi temasuk penyakit terbanyak nomor 2 dengan jumlah 145,534 dan berdasarkan Profil Dinas Kesehatan Kota Mataram dari 11 puskesmas yang ada di Kota Mataram Puskesmas Cakranegara termasuk puskesmas dengan angka kejadian penyakit hipertensi tertinggi dengan jumlah 854 jiwa pertahun dengan jumlah lansia hipertensi sebanyak 151 perbulannya. Wilayah kerja Puskesmas Cakranegara yang paling banyak dijumpai kejadian hipertensi pada lansia adalah di wilayah kelurahan Turida yaitu sebanyak 85 jiwa. Faktor keturunan dan gaya hidup menurut hasil penelitian merupakan penyebab utama hipertensi. Seseorang yang menderita hipertensi mempunyai resiko penyakit jantung dua kali dan penyakit stroke delapan kali dibandingkan orang dengan tensi normal (Widharto, 2009). Hal ini juga ditegaskan oleh Katzung (2007), bahwa hipertensi yang menetap akan merusak pembuluh darah ginjal, jantung, dan otak serta menyebabkan peningkatan gagal ginjal, penyakit koronaria, gagal jantung, stroke, dan demensia. Hipertensi selain mengakibatkan angka kematian yang tinggi (high case fatality rate) juga berdampak kepada penurunan kualitas hidup (Sudarmako, 2008). Tata laksana untuk hipertensi adalah secara farmakologis dan non farmakologis (Sudoyo, 2006). Secara nonfarmakologis salah satunya adalah olahraga. Olahraga yang dianjurkan untuk pasien hipertensi adalah olahraga yang dilakukan secara khusus, yaitu olahraga yang dilakukan secara bertahap dan 
tidak boleh memaksakan diri, antara lain senam hipertensi (Armilawati, 2007). Senam hipertensi merupakan olahraga yang ditunjukkan untuk penderita hipertensi dan usia lanjut untuk mengurangi berat badan dan mengelola stres (faktor yang mempertinggi hipertensi) yang dilakukan selama 30 menit dan dilakukan seminggu minimal 2x (Sherwood, 2005 dalam Totok dan Rosyid, 2017). Tujuan lain adalah untuk meningkatkan aliran darah dan pasokan oksigen ke dalam otot-otot dan rangka yang aktif khususnya terdapat otot jantung sehingga dapat menurunkan tekanan darah. Setelah beristirahat pembuluh darah akan berdilatasi atau meregang, dan aliran darah akan turun sementara waktu, sekitar 30-120 menit kemudian akan kembali pada tekanan darah sebelum senam. Jika melakukan olahraga secara rutin dan secara terus menerus, maka pembuluh darah akan lebih elastis dan penurunan tekanan darah akan berlangsung lebih lama. Sehingga dengan melebarnya pembuluh darah, tekanan darah akan menurun setelah melakukan aktifitas olahraga (Totok dan Rosyid, FN, 2017). Hasil wawancara pada bulan Maret 2019 di Puskesmas Cakranegara terdapat 9 dari 10 lansia hipertensi belum mengetahui senam hipertensi yang dapat menurunkan tekanan darah, pasien mengatakan hanya mengetahui diet dan meminum obat secara teratur dapat mengontrol tekanan darah dan belum pernah dilakukan penelitian tentang senam hipertensi di Puskesmas Cakranegara. Tujuan penelitian ini adalah untuk mengetahui pengaruh senam hipertensi lansia terhadap tekanan darah lansia dengan hipertensi di wilayah kerja Puskesmas Cakranegara Kelurahan Turida Tahun 2019.

\section{METODE}

Penelitian ini menggunakan desain pra-eksperimen dengan rancangan one group pretestposttest. Populasi dalam penelitian ini adalah semua lansia hipertensi dengan usia 55-64 tahun yang berada di wilayah kerja Puskesmas Cakranegara Kelurahan Turida. Wilayah Kerja Puskesmas Cakranegara Kelurahan Turida merupakan salah satu tempat kejadian lansia hipertensi tertinggi pada tahun 2017, yaitu sebanyak 85 jiwa. Sampel dalam penelitian ini adalah lansia hipertensi dengan usia 55-64 tahun yang berada di wilayah kerja Puskesmas Cakranegara Kelurahan Turida yang memenuhi kriteria inklusi. Tehnik sampling adalah purposive sampling dan besar sampel adalah 30 orang. Kriteria inklusi adalah : (1) bersedia menjadi responden, (2) kelompok umur usia lanjut (55-64 tahun), (3) klien dengan hipertensi primer, (4) tidak terdapat penyakit penyerta atau komplikasi lain, dan (5) tidak cacat fisik. Sebagaimana yang dikemukakan oleh Baley dalam Mahhud (2011) bahwa untuk penelitian yang menggunakan analisis data statistic, ukuran sampel paling minimum adalah 30 (Lestari, 2014). Intervensi yang diberikan berupa senam hipertensi lansia sebanyak 2 kali seminggu selama empat (4) minggu. Pengumpulan data dengan observasi tekanan darah sebelum dan sesudah intervensi. Data dianalisa menggunakan uji paired sampel $t$-test dengan tingkat kemaknaan $95 \%(\alpha=$ $0,05)$.

\section{HASIL PENELITIAN}


Hasil penelitian tentang karakteristik responden penelitian didapatkan bahwa jenis kelamin yang terbanyak adalah perempuan sebanyak 25 orang $(83,33 \%)$, dan berdasarkan riwayat penyakit, sebanyak 20 orang $(66,67 \%)$ menderita hipertensi, 6 orang $(20 \%)$ mengalami hipertensi dan artritis dan sisanya sebanyak 4 orang $(13,33 \%)$ mengalami hipertensi dan konstipasi. Hasil penelitian tentang tekanan darah responden sebelum senam hipertensi lansia dapat dilihat pada table 1 dan tabel 2 berikut :

Tabel 1. Distribusi Tekanan Darah Lansia Hipertensi Sebelum Senam Hipertensi Lansia di wilayah kerja Puskesmas Kelurahan Turida, tanggal 01- 23 Juni 2019

\begin{tabular}{|c|c|c|c|}
\hline No & Klasifikasi Hipertensi & $\mathrm{n}$ & Persentase \\
\hline 1 & Hipertensi Stadium 1 & 23 & 76.67 \\
\hline 2 & Hipertensi Stadium 2 & 7 & 23.33 \\
\hline \multicolumn{2}{|l|}{ Total } & 30 & 100.00 \\
\hline
\end{tabular}

Sumber : Data primer, 2019

Berdasarkan tabel 1, menunjukkan bahwa responden terbanyak adalah responden yang termasuk dalam hipertensi stadium 1 yaitu 23 orang (76.67\%).

Tabel 2. Rata-Rata (Mean) Tekanan Darah Lansia Hipertensi Sebelum Senam Hipertensi Lansia di wilayah kerja Puskesmas Cakranegara Kelurahan Turida, tanggal 0123 Juni 2019

\begin{tabular}{|c|c|c|c|c|}
\hline Parameter & Rata-Rata & $\begin{array}{c}\text { Standar } \\
\text { Deviasi }\end{array}$ & Nilai Minimum & $\begin{array}{c}\text { Nilai } \\
\text { Maksimum }\end{array}$ \\
\hline $\begin{array}{c}\text { Tekanan Darah } \\
\text { Sistolik Sebelum } \\
\text { Intervensi }\end{array}$ & 151,80 & 7,739 & 141 & 167 \\
\hline $\begin{array}{c}\text { Tekanan Darah } \\
\text { Diastolik } \\
\text { Sebelum } \\
\text { Intervensi }\end{array}$ & 94,73 & 3,841 & 90 & 103 \\
\hline
\end{tabular}

Sumber : Data primer, 2019

Berdasarkan tabel 2, menunjukkan bahwa rata-rata nilai tekanan darah sistolik sebelum intervensi yaitu 151,80 dan rata-rata nilai tekanan darah diastolik adalah 94,73.

Hasil penelitian tentang tekanan darah setelah senam hipertensi lansia dapat dilihat pada tabel 3 dan tabel 4 berikut :

Tabel 3. Distribusi Tekanan Darah Lansia Hipertensi Sesudah Senam Hipertensi Lansia di wilayah Puskesmas Cakranegara Kelurahan Turida, tanggal 01 - 23 Juni 2019

\begin{tabular}{|c|c|c|c|}
\hline No & Klasifikasi Hipertensi & $\mathrm{n}$ & Persentase \\
\hline 1 & Pre Hipertensi & 22 & 73,33 \\
\hline 2 & Hipertensi Stadium 1 & 6 & 20.00 \\
\hline 3 & Hipertensi Stadium 2 & 2 & 06,67 \\
\hline \multicolumn{2}{|c|}{ Total } & 30 & 100.00 \\
\hline
\end{tabular}

Sumber : Data primer, 2019

Berdasarkan tabel 3, menunjukkan bahwa responden terbanyak adalah responden yang termasuk dalam kategori prehipertensi yaitu 22 orang $(73,33 \%)$.

Tabel 4. Rata-Rata Tekanan Darah Lansia Hipertensi Sesudah Senam Hipertensi Lansia di wilayah Puskesmas Cakranegara Kelurahan Turida, tanggal 01 - 23 Juni 2019 


\begin{tabular}{|c|c|c|c|c|}
\hline Parameter & Rata-Rata & $\begin{array}{c}\text { Standar } \\
\text { Deviasi }\end{array}$ & Nilai Minimum & $\begin{array}{c}\text { Nilai } \\
\text { Maksimum }\end{array}$ \\
\hline $\begin{array}{c}\text { Tekanan Darah } \\
\text { Sistolik Sesudah } \\
\text { Intervensi }\end{array}$ & 137,13 & 9,258 & 126 & 162 \\
\hline $\begin{array}{c}\text { Tekanan Darah } \\
\text { Diastolik } \\
\text { Sesudah } \\
\text { Intervensi }\end{array}$ & 90,27 & 4,394 & 84 & 100 \\
\hline
\end{tabular}

Sumber : Data primer, 2019

Berdasarkan tabel 4, menunjukkan bahwa rata-rata nilai tekanan darah sistolik sesudah intervensi yaitu 137,13 dan rata-rata nilai tekanan darah diastolik sesudah intervensi yaitu 90,27 .

Hasil analisa statistic terhadap tekanan darah responden sebelum dan setelah senam hipertensi lansia dapat dilihat pada tabel 5 berikut :

Tabel 5. Hasil Uji Paired Sampel T-Test Pengaruh Senam hipertensi lansia Terhadap Tekanan Darah Lansia Hipertensi di wilayah kerja Puskesmas Cakranegara Kelurahan Turida, tanggal 01 - 23 Juni 2019.

\begin{tabular}{|l|l|c|c|c|c|}
\hline \multirow{2}{*}{ No } & \multirow{2}{*}{ Keterangan } & \multicolumn{2}{c|}{ Sebelum } & \multicolumn{2}{c|}{ Sesudah } \\
\cline { 3 - 6 } & & Sistolik & Diastolik & Sistolik & Diastolik \\
\hline 1. & $\Delta$ Tekanan darah & 151.80 & 94.73 & 90.27 & 90.27 \\
\hline 2. & St. Deviasi & 7.739 & 3.841 & 4.394 & 4.394 \\
\hline 3. & Sig & \multicolumn{2}{|c|}{0.000} & \multicolumn{2}{c|}{0.000} \\
\hline
\end{tabular}

Sumber : Data primer, 2019

Ket $: \Delta \quad:$ Rata-rata tekanan darah

Berdasarkan tabel 5, hasil perhitungan dengan uji Paired Sampel T-Test pada sistem komputerisasi SPSS 16.0, untuk pengaruh senam hipertensi lansia terhadap tekanan darah lansia hipertensi dengan analisis statistik pada $\alpha=0,05$ diperoleh $p=0,000<\alpha=0,05$ yang berarti hipotesa nol $\left(\mathrm{H}_{0}\right)$ ditolak atau hipotesa kerja $\left(\mathrm{H}_{1}\right)$ diterima, yang artinya ada pengaruh senam hipertensi lansia terhadap tekanan darah lansia hipertensi di wilayah kerja Puskesmas Cakranegara Kelurahan Turida tahun 2019.

\section{PEMBAHASAN}

Hasil penelitian tentang jenis kelamin didapatkan bahwa 83,33\% responden berjenis kelamin perempuan. Adib (2010) menyatakan bahwa perubahan hormonal yang sering terjadi pada wanita lebih cenderung memiliki tekanan darah tinggi. Berkaitan dengan hipertensi, laki-laki mempunyai resiko lebih tinggi untuk menderita hipertensi lebih awal. Sedangkan pada perempuan, lebih rentan terhadap hipertensi ketika berumur di atas 50 tahun (Susilo, 2010). Setelah menopouse, wanita umumnya memiliki tekanan darah lebih tinggi dari sebelumnya (Berman, 2009). Perempuan yang belum menopouse dilindungi oleh hormon estrogen yang berperan dalam meningkatkan kadar HDL. 
Kadar kolesterol HDL (High Density Lipoprotein) rendah dan tingginya kolesterol LDL (Low Density Lipoprotein) mempengaruhi terjadinya proses aterosklerosis dan mengakibatkan tekanan darah tinggi (Anggraini dkk, 2009). Jadi hasil penelitian ini terkait jenis kelamin sejalan dengan teori diatas.

\section{Identifikasi Tekanan Darah Lansia Hipertensi Sebelum Melakukan Senam Hipertensi Lansia}

Berdasarkan data hasil penelitian, diketahui bahwa rata-rata tekanan darah lansia sebelum melakukan senam hipertensi lansia selama penelitian berlangsung yaitu tekanan darah sistolik 151,80 mmHg dan tekanan darah diastolik yaitu $94,73 \mathrm{mmHg}$. Hal ini termasuk dalam kategori hipertensi stadium I dimana tekanan darah sistolik 140 - 159 mmHg dan tekanan darah diastolik 90 - $99 \mathrm{mmHg}$ ( JNC VIII). Tekanan darah meningkat disebabkan karena proses penuaan dan terjadi perubahan sistem kardiovaskuler baik secara strukturual maupun fisiologis. Selain itu juga dipengaruhi oleh pola makan dan gaya hidup seperti kurang berolahraga (Lueckenotte, 2007 dalam Sukma 2017). Orang yang tidak berolahraga pada umumnya cenderung mengalami kegemukan, stres. Hal tersebut dapat merangsang hormon adrenalin yang menyebabkan jantung berdenyut lebih cepat dan penyempitan kapiler sehingga tekanan darah meningkat (Setiawan, 2008). Berdasarkan dari hasil penelitian yang ditemukan oleh peneliti bahwa hasil ini sesuai dengan teori yang diatas, dimana rata-rata tekanan darah responden sebelum melakukan senam hipertensi lansia termasuk dalam kategori hipertensi stadium I. Hal ini disebabkan karena selain faktor usia, berdasarkan wawancara responden jarang melakukan aktifitas fisik maupun olahraga. Sebagian besar responden mengaku tidak mengetahui bahwa aktifitas fisik dan olahraga yang rutin dapat menurunkan tekanan darah. Responden mengaku hanya mengkonsumsi obat jika penyakit kambuh. Selain itu, beberapa responden terutama responden dengan jenis kelamin laki-laki mengaku memiliki kebiasaan atau gaya hidup yang memicu kejadian hipertensi seperti merokok dan mengkonsumsi kopi. Nikotin yang dihisap akan masuk ke dalam aliran darah dapat merusak lapisan endotel pembuluh darah arteri dan mengakibatkan proses arteriosclerosis dan tekanan darah tinggi (Rahajeng dan Tuminah, 2009). Otak akan bereaksi terhadap nikotin dengan memberi sinyal pada kelenjar adrenal untuk melepaskan epinefrin (adrenalin). Hormon ini akan menyebabkan penyempitan pembuluh darah dan dengan demikian memaksa jantung untuk bekerja lebih berat karena tekanan yang lebih tinggi (Nurwidanti \& Wahyuni, 2013). Efek lain nikotin adalah berkumpulnya trombosit, trombosit akan menggumpal dan akhirnya menyumbat pembuluh darah yang sudah sempit akibat asap yang mengandung CO yang berasal dari rokok (Price \& Wilson, 2006). Penyebab hipertensi yang dialami responden tidak dapat hanya dilihat dari satu aspek saja namun dilihat secara menyeluruh.

\section{Identifikasi Tekanan Darah Lansia Hipertensi Sesudah Melakukan Senam Hipertensi Lansia}

Berdasarkan data hasil penelitian, diketahui bahwa rata-rata tekanan darah lansia sesudah melakukan senam hipertensi lansia selama peneliian berlangsung yaitu tekanan darah sistolik 131,13 $\mathrm{mmHg}$ dan rata-rata tekanan darah diastolik yaitu 90,27 $\mathrm{mmHg}$. Hal ini termasuk dalam kategori pre 
hipertensi yaitu tekanan darah sistolik 120 - $139 \mathrm{mmHg}$ dan tekanan darah diastolik 80-89 $\mathrm{mmHg}$ (JNC VII). Menurut teori (Smeltzer, 2012) penurunan tekanan darah terjadi karena pembuluh darah mengalami pelebaran dan relaksasi. Semakin lama latihan olahraga dapat melemaskan pembuluhpembuluh darah karena olahraga dapat mengurangi tahanan perifer. Otot jantung pada orang yang rutin berolahraga sangat kuat sehingga otot jantung pada individu tersebut berkontraksi lebih sedikit dari pada otot jantung individu yang jarang berolahraga, karena olahraga dapat dapat menyebabkan penurunan denyut jantung dan olahraga juga akan menurunkan cardiac output, yang akhirnya dapat menurunkan tekanan darah. Berdasarkan dari hasil penelitian yang ditemukan oleh peneliti bahwa hasil penelitian ini sesuai dengan teori yang diatas. Setelah dilakukannya senam hipertensi lansia, ratarata tekanan darah responden mengalami penurunan dan termasuk dalam kategori pre hipertensi yaitu tekanan darah sistolik 120 - $139 \mathrm{mmHg}$ dan tekanan darah diastolik 80-89 mmHg (JNC VII). Selain itu, sebagian besar responden mengatakan tubuhnya menjadi lebih segar, bugar dan sehat.

\section{Menganalisa Pengaruh Senam hipertensi lansia Terhadap Tekanan Darah Lansia Hipertensi}

Berdasarkan hasil uji statistik menunjukkan $\rho=0,000(<\alpha=0,05)$ sehingga dapat disimpulkan bahwa ada pengaruh senam hipertensi lansia terhadap tekanan darah lansia hipertensi. Hal ini berarti setelah melakukan senam hipertensi lansia, tekanan darah lansia hipertensi mengalami penurunan dibandingkan sebelum melakukan senam hipertensi lansia. Hasil penelitian ini sesuai dengan teori Sylvia (2003), bahwa senam hipertensi lansia adalah olahraga yang disusun dengan selalu mengutamakan kemampuan jantung, gerakan otot besar, dan kelenturan sendi, serta memasukkan oksigen sebanyak mungkin. Selain meningkatnya perasaan sehat dan kemampuan untuk mengatasi stress keuntungan lain dari senam jantung yang teratur adalah menurunnya tekanan darah, berkurangnya obesitas, berkurangnya frekuensi saat istirahat dan menurunnya resistensi insulin. Hasil penelitian ini sejalan dengan penelitian yang dilakukan dengan Liza (2015) kegiatan dilakukan selama empat minggu pada 15 orang lansia dengan hipertensi ringan sampai sedang, dari 15 responden melaksanakan senam hipertensi lansia selama 1x seminggu dengan durasi \pm 30 menit. Sebelum melakukan senam hipertensi lansia rata-rata tekanan darah sistolik lansia hipertensi adalah 145,33 $\mathrm{mmHg}$, rata-rata tekanan darah diastolik adalah $88,00 \mathrm{mmHg}$. Setelah melakukan senam hipertensi lansia sebagian besar responden mempunyai tekanan darah pre hipertensi dimana rata-rata tekanan darah sistolik adalah $137,33 \mathrm{mmHg}$, rata-rata tekanan darah diastolik adalah $82,00 \mathrm{mmHg}$. Analisa senam hipertensi lansia sesuai dengan teori yang dikemukakan oleh Maryam (2008) pada usia lanjut kekuatan mesin pompa jantung berkurang. Berbagai pembuluh darah penting khusus di jantung dan di otak mengalami kekakuan. Dengan latihan fisik atau senam dapat membantu kekuatan pompa jantung bertambah karena otot jantung pada orang yang rutin berolahraga sangat kuat sehingga otot jantung pada individu tersebut berkontaksi lebih sedikit dari pada otot jantung individu yang jarang berolahraga, karena olahraga dapat menyebabkan penurunan denyut jantung dan olahraga juga akan menurunkan cardiac output, yang akhirnya dapat menurunkan tenanan darah sesuai dengan teori yang 
dikemukakan oleh (Smeltzer, 2012), sehingga aliran darah bisa kembali lancar. Jika dilakukan secara teratur akan memberikan dampak yang baik bagi lansia terhadap tekanan darahnya. Hasil penelitian Rizki M (2016) juga menunjukkan bahwa olahraga senam hipertensi lansia dengan tekanan darah khususnya pada lansia cukup efektif dalam menurunkan tekanan darah yang dilakukan 6 kali berturutturut. Senam dilakukan 3 hari selama 3 minggu dengan hasil rata-rata penurunan tekanan darah sistolik adalah $11,26 \mathrm{mmHg}$ dan rata-rata penurunan tekanan darah diastolik adalah $18,48 \mathrm{mmHg}$. Hasil penelitian ini sesuai dengan teori yang diatas. Peneliti berpendapat bahwa senam hipertensi lansia dapat menurunkan tekanan darah sistolik adalah $14,67 \mathrm{mmHg}$ dan tekanan darah diastolik adalah 4,46 mmHg. Hasil wawancara dengan responden didapatkan mereka merasa lebih segar, bugar dan sehat setelah melakukan senam hipertensi lansia, yang dibarengi dengan menggunakan obat tradisional dan obat farmakologi diberikan 1 kali seminggu.

\section{KESIMPULAN}

Dari hasil penelitian dapat disimpulkan bahwa rata-rata tekanan darah sistolik sebelum dilakukan senam hipertensi lansia yaitu $151,80 \mathrm{mmHg}$, rata-rata tekanan darah diastolik yaitu 94,73 mmHg. Sebagian besar responden masuk dalam klasifikasi hipertensi stadium 1 sebanyak 23 orang. Rata-rata tekanan darah sistolik sesudah dilakukan senam hipertensi lansia yaitu $137,13 \mathrm{mmHg}$, rata-rata tekanan darah diastolik yaitu 90,27 mmHg. Yang terbanyak rmasuk dalam klasifikasi pre hipertensi sebanyak 22 orang. Berdasarkan hasil uji menggunakan paired sampel $t$ test diperoleh $p=0,000$ $<\alpha=0,05$, dengan demikian dapat disimpulkan bahwa, $\mathrm{H}_{0}$ ditolak $\mathrm{H}_{1}$ diterima berarti senam hipertensi lansia berpengaruh terhadap tekanan darah lansia hipertensi.

\section{DAFTAR PUSTAKA}

Adib, Miller. 2010. Cara Mudah Memahami dan Menghindari Hipertensi, Jantung dan Stroke. Yogyakarta : Dianloka Pustaka

Arif M. 2013. Kapita Selekta Kedokteran Jilid I: Nefrologi dan Hipertensi. Jakarta: Media Aesculapius FKUI.

Anggraini, dkk. 2009. Faktor- Faktor yang Berhubungan dengan Kejadian Hipertensi Pada Pasien yang berobat di Poliklinik Dewasa Puskesmas Bangkinang Periode Januari 2009

Berman, A. 2009. Buku Ajar Praktik Keperawatan Klinis Kozier \& Erb, Alih Bahasa Meiliya dkk, EGC. Jakarta.

Dinas Kesehatan Provinsi NTB. 2017. Profil Kesehatan Provinsi NTB. Nusa Tenggara Barat.

Fatimah. 2010. Merawat Manusia Lanjut Usia Suatu Pendekatan Proses Keperawatan Gerontik. Jakarta : TIM.

Katzung, B.G., 2007, Vasodilator \& Terapi Angina Pektoris, dalam Katzung, B.G., Farmakologi Dasar \& Klinik (Basic \& Clinical Pharmacology), edisi 10, Penerbit Buku Kedokteran, EGC, Jakarta 
Kushariyadi, 2011. Terapi Modalitas Keperawatan pad Klien Psikogeriatrik. Jakarta: Media Selemba. Hal. 143

Liza, Merianti. Wijaya, Krisna. 2015. Pelaksanaan Senam Jantung Sehat Untuk Menurunkan Tekanan Darah Pada Pasien Hipertensi Di Panti Sosial Tresna Wherda Kasih Sayang Ibu Batu Sangkar. Jurnal Stikes Yarsi. Vol 1 Lombok Barat. Tabel: 24.

Maryam, R.S.dkk. 2008. Mengenal usia lanjut dan perawatannya. Salemba Medika. Jakarta.

Nurwidanti, L. Wahyuni, C.U. 2013. Analisis Pengaruh Paparan Asap Rokok Di Rumah Pada Wanita terhadap Kejadian Hipertensi. Jurnal Berkala Epidemiologi Volume 1 Nomor 2.

Perhimpunan Dokter Spesialis Kardiovaskular Indonesia (PERKI). 2015. Pedoman Tatalaksana Hipertensi Pada Penyakit Kardiovaskular.

Potter\&Perry. 2013. Buku Ajar Fundamental Keperawatan. EGC: Jakarta.

Profil Dinas Kesehatan Provinsi Nusa Tenggara Barat, 2016.

Riset kesehatan Dasar. 2018. Pedoman Pengukuran dan Pemeriksaan. Badan Penelitian dan Pengembangan Kesehatan Departemen Kesehatan RI, Jakarta.

Rizki, M (2016). Hubungan Tingkat Pendidikan dan Aktivitas Fisik dengan Fungsi Kognitif pada Lansia di Kelurahan Darat. Tesis FK USU..

Setiawan dkk. 2008. Hubungan Frekuensi Senam Lansia Terhadap Tekanan Darah dan Nadi Pada Lansia Hipertensi, Proseding Konferensi Nasional II PPNI Jawa Tengah

Sylvia. 2003. Buku ajar Senam Jantung Sehat. Edisi 1. Yogyakarta: Graha Ilmu.

Smeltzer, S. C., Bare, B. G., 2012, “Buku Ajar Keperawatan Medikal-Bedah Brunner \&Suddarth. Vol. 2. E/8", EGC, Jakarta.

Widharto. 2009. Bahaya Hipertensi. Sunda Kelapa Pustaka.Jakarta. Divine, Jon G. 2012. Program Olahraga Tekanan Darah Tinggi. PT Citra Aji Parama. Yogyakarta. 